University of Wollongong

Research Online

Faculty of Social Sciences - Papers (Archive) Faculty of Arts, Social Sciences \& Humanities

2014

Steady state visually evoked potential (SSVEP) phase change as an index of Spatial Working Memory task performance: The influence of nootropic supplementation

David A. Camfield

University of Wollongong, camfield@uow.edu.au

Andrew Scholey

Swinburne University of Technology, andrew@scholeylab.com

Richard B. Silberstein

Swinburne University

Andrew Pipingas

Swinburne University of Technology, apipingas@swin.edu.au

Con Stough

Swinburne University of Technology, cstough@swin.edu.au

Follow this and additional works at: https://ro.uow.edu.au/sspapers

Part of the Education Commons, and the Social and Behavioral Sciences Commons

Research Online is the open access institutional repository for the University of Wollongong. For further information contact the UOW Library: research-pubs@uow.edu.au 
Steady state visually evoked potential (SSVEP) phase change as an index of Spatial Working Memory task performance: The influence of nootropic supplementation

\author{
Abstract \\ Abstract presented at the 17th World Congress of Psychophysiology (IOP2014) of the International \\ Organization of Psychophysiology (IOP) Hiroshima, Japan, September 23rd to 27th, 2014 \\ Keywords \\ influence, nootropic, supplementation, task, memory, working, spatial, index, change, performance, phase, \\ steady, ssvep, potential, evoked, visually, state \\ Disciplines \\ Education | Social and Behavioral Sciences \\ Publication Details \\ Camfield, D. A., Scholey, A., Silberstein, R., Pipingas, A. \& Stough, C. (2014). Steady state visually evoked \\ potential (SSVEP) phase change as an index of Spatial Working Memory task performance: The influence \\ of nootropic supplementation. International Journal Of Psychophysiology, 94 (2), 185.
}

This journal article is available at Research Online: https://ro.uow.edu.au/sspapers/1273 


\section{Steady state visually evoked potential (SSVEP) phase change as an index of Spatial Working Memory task performance: The influence of nootropic supplementation}

David A. Camfield ${ }^{a, b}$

Andrew Scholey ${ }^{b}$

Richard Silberstein ${ }^{\mathrm{b},}$

Andrew Pipingas ${ }^{b}$,

Con Stough ${ }^{b}$

${ }^{a}$ School of Psychology, University of Wollongong, Australia

${ }^{b}$ Centre for Human Psychopharmacology, Swinburne University of Technology, Australia

Background: Spatial Working Memory (SWM) is a cognitive domain that has a high degree of sensitivity to pharmaceutical intervention and is one of the first domains to be adversely impacted by age-related cognitive decline. Steady State Probe Topography (SST) at a frequency of $13 \mathrm{~Hz}$ is a novel electrophysiological technique that enables investigation into SSVEP amplitude and phase change with a precise temporal resolution of $<80 \mathrm{~ms}$.

Methods: The following presentation will detail a program of research conducted at the Centre for Human Psychopharmacology since 2009 which has involved randomized placebo-controlled nootropic intervention studies of SSVEP changes during SWM task performance (with a combined $\mathrm{N}$ of 200 people). Nootropic substances that have been administered include Cocoa Polyphenols, Panax quinquefolius (American ginseng), Ginkgo biloba, Hypericum perforatum, Guarana and Bvitamins.

Results: SSVEP phase lag in posterior-parietal and prefrontal brain regions during the online maintenance of spatial locations in WM has been found to be increased in response to nootropic supplementation.

Conclusions: These studies provide preliminary evidence to suggest that the typical SSVEP phase advance observed under conditions of increased WM load may be ameliorated by nootropic intervention - a finding that may be explained by increases in inhibitory neural processes. 